\title{
Coronavirus Disease 2019 Transmission: Blood Viremia and Aerosol Generation from Spinal Surgery. Is There an Increased Risk to the Surgical Team?
}

\author{
Siddharth Shah, Akshay Gadiya, Mohammed Shakil Patel, Masood Shafafy \\ The Centre for Spinal Studies and Surgery, Queens Medical Centre, Nottingham University Hospitals NHS Trust, Nottingham, UK
}

\begin{abstract}
As a respiratory pathogen, the novel coronavirus is commonly associated with aerosol-generating procedures. However, it is currently unclear whether spinal surgical procedures pose an additional risk of viral transmission to the surgical team. We reviewed the available evidence to ascertain the presence of coronavirus disease 2019 (COVID-19) blood viremia and the virus' blood transmissibility, as well as evidence of blood-aerosol generation and operating room contamination from spinal surgical procedures. There is established evidence of COVID-19 blood viremia, a viral pathogenic cycle via angiotensin-converting enzyme 2 (ACE-2) receptors and similar blood transmission risk data from the SARS (severe acute respiratory syndrome)/MERS (Middle East respiratory syndrome) era. Spinal surgical practices demonstrate significant blood-aerosol generation from the operative wound due to the use of common surgical instruments, such as electrocautery, as well as high-speed and high-impact devices. Based on the evidence, there is an established additional risk of viral transmission faced by surgical teams from blood-aerosols generated from the operative wound of COVID-19infected patients via the inhalation of virus-laden aerosols and the subsequent initiation of the viral pathogenic cycle through binding with pulmonary ACE-2 receptors. Recognizing this additional risk amidst the ongoing pandemic serves as a caution to front-line surgical personnel to strictly adhere to personal protective equipment usage in operating rooms, to modify surgical techniques to reduce the hazard of surgical aerosol generation and COVID-19 viral exposure, and to consider it as an integral aspect of planning and adapting to the "new normal" operating practices.
\end{abstract}

Keywords: COVID-19; Spinal surgery; Aerosol generation; Blood viremia; Viral transmission

\section{Introduction}

In December 2019, a series of pneumonia cases of unknown etiology emerged in the Hubei province of China, with clinical presentations greatly resembling that of viral pneumonia. Deep sequencing analysis from lower respira- tory tract samples indicated a novel coronavirus $(\mathrm{CoV})$, which was named coronavirus disease 2019 (COVID-19) $[1,2]$. The infection, which originated in Wuhan, rapidly spread to other countries and was declared a worldwide pandemic on March 11, 2020 [3]. By May 26, 2020, there were 5,404,512 total cases confirmed and 343,514 deaths

Received Jul 20, 2020; Accepted Sep 7, 2020

Corresponding author: Siddharth Shah

The Centre for Spinal Studies and Surgery, Queens Medical Centre, Nottingham University Hospitals NHS Trust, Nottingham, NG7 $2 \mathrm{UH}, \mathrm{UK}$

Tel: +44-745-921-2261, Fax: +44-0115-9709991, E-mail: siddharth.shah@nuh.nhs.uk 
reported by the World Health Organization (WHO) [4]. In the absence of mass testing, these figures are likely to greatly underestimate the total disease burden. In the absence of any available protective vaccine, minimizing person-to-person transmission has been the most important aim of the lockdown and social distancing measures to limit viral transmission. Given they are on the front lines, healthcare workers are the group most exposed to the COVID-19 virus, and the additional shortage of personal protective equipment (PPE) has resulted in a rising infection rate among healthcare staff [5].

COVID-19 transmission occurs in the form of virusbearing respiratory droplets, which exposes surgeons, anesthetists, and other operating room staff alike. Viral colonization of the respiratory tract's mucosal surface gives rise to a direct increase in viral exposure for certain specialties, such as anesthetists during endotracheal intubation, otolaryngologists performing upper airway procedures, endoscopic surgeons performing upper gastrointestinal endoscopic procedures, and neurosurgeons performing endonasal or skull base procedures with the potential of paranasal sinus breach [6,7]. Interest has focused on the respiratory transmission of the COVID-19 virus via aerosols, and there has been substantial research focusing on these aerosol-generating procedures. The Centers for Disease Control and Prevention lists aerosolgenerating procedures as those that primarily involve the respiratory tract [8]. The Royal College of Surgeons of England, however, lists all surgical procedures involving high-speed devices as aerosol-generating [9].

The use of PPEs during surgical procedures, although protective, can be uncomfortable, especially during prolonged operations. There are also significant concerns with regard to the shortage of PPEs in some hospitals [5]. These factors, along with the assumption that this virus can only be spread via respiratory droplets, has led to some institutions to use PPEs only during intubation or extubation procedures; once a closed ventilatory system has been established, some operating surgeons cease taking optimal protective measures.

Despite the numerous recent publications focusing on aerosol generation from surgical procedures, two aspects remain unclear: (1) whether this "respiratory-transmitted pathogen" has a proportionate viral load in the bloodstream, which could cause viral transmission via blood and/or blood-aerosols; and (2) whether surgical procedures can generate such blood-aerosols to potentially incite viral transmission. Orthopedic surgeons are recognized as having the highest risk of occupational exposure to a patient's blood in the form of aerosol inhalation or direct splatter [10]. Aerosolization of virus-laden blood particles could represent an additional risk for surgical teams in these trying times. It remains unclear; however, whether spinal surgery in itself causes added bloodaerosol generation from the operative wound and whether there is an increased risk of viral transmission from these aerosols to the surgical team.

The purpose of this study was to review and summarize the available literature to answer the questions raised above. Is there evidence for the presence of the COVID-19 virus in the blood of infected patients? Can the virus-laden blood be aerosolized into droplets? What components of spinal surgical procedures generate aerosols? Can these procedures pose an additional risk of viral transmission to the surgical team? Is there evidence to support this pathogen's spread from blood-aerosols to respiratory tracts?

\section{Review Methodology}

We searched the electronic databases (PubMed, MEDLINE, Google Scholar, and references from relevant articles) on June 3, 2020 for relevant English-language research articles, with two broad objectives: (1) to identify available research focusing on the biology of the COVID-19 virus cycle and its transmission to ascertain the possibility of the virus' presence in blood and blood-aerosols; and (2) to review the available literature on aerosol generation from spinal surgical procedures. The keywords used in combination were "coronavirus," "novel coronavirus," "COVID-19," "aerosol generation," "aerosols," "blood-aerosol," "viral transmission," "contamination," "surgical team," "high-speed instruments," and "spinal surgery." The final step was assimilation of the literature reviews on both these aspects to deduce whether there is an increased risk of viral transmission to the surgical team through spinal surgical procedures.

\section{Results and Discussion}

\section{Biology of COVID-19 virus: do we need to worry about viral presence in blood-aerosols?}

The discovery of this novel coronavirus in a population exposed to a wet animal market in Wuhan established 
its animal origin, with bats identified as the intermediate carrier for transmission to humans. The further human spread of the infection was attributed to person-to-person transmission by droplets spread through coughing and sneezing or by direct contact.

Although respiratory tract shedding is the primary mode of transmission, numerous early studies from China using real-time reverse transcriptase polymerase chain reaction (PCR) testing isolated live COVID-19 virus from other body specimens, including blood. Wang et al. [11] isolated the virus in $1 \%$ of tested blood samples and postulated that the occurrence of the live virus in the bloodstream might reflect a more systemic nature for the infection than just a localized respiratory mucosal disease. In one of their earliest studies on a COVID-19-infected patient cohort in Wuhan, Zhang et al. [12] reported a $40 \%$ positivity rate for viral cultures from blood samples from a group of 15 patients who were tested after days of medical treatment, some of who tested negative with the oral swab, thereby highlighting the virus' significant presence in blood. In another report from Wuhan, Huang et al. [2] reported 15\% rate of COVID-19 blood viremia in the 41 initially positive patients in the city. Similar findings were reported from Guangzhou, China, where Chen et al. [13] reported a $10.5 \%$ rate of viral RNA detection in blood among 57 patients with confirmed coronaviral disease. These findings reflect the definite blood viremia of the COVID-19 virus, varying over a wide range from $1 \%-40 \%$ positivity. In a small retrospective study, Chen et al. [14] found no evidence of blood-to-blood gestational maternal-fetal transmission of infection from a COVID19-positive mother. Since all of the mothers in this cohort underwent elective cesarean section, the question still remains as to whether transmission can occur during a vaginal delivery.

There is also evidence of blood transmission from the literature and evidence from the severe acute respiratory syndrome (SARS) (2002) and Middle East respiratory syndrome (MERS) (2012) epidemics, both of which belong to the same $\beta$-coronaviridae viral subgroup [15]. Chang et al. [16] extensively reviewed $\mathrm{CoV}$ and blood safety and concluded that viral RNA can be demonstrated during various periods after symptom onset and can be detected from plasma or serum from patients infected with SARS-CoV (2002), MERS-CoV (2012), and SARSCoV-2/COVID-19 (2019). Although the WHO noted in 2003 that no cases of SARS-CoV have been reported due to the transfusion of blood products, the WHO and the U.S. Food and Drug Administration indicated an identified theoretical risk of SARS-CoV transmission through transfusion, and subsequently recommended deferring donation from potentially infected donors and recalling or contact tracing the recipients of blood donated from infected donors [16]. Researchers also demonstrated that the SARS virus had an affinity to (and could also replicate in) lymphocytes in blood, indicating a potential for transmission by blood or blood products with a high concentration of lymphocytes. In April 2003, the mean theoretical risk of SARS-CoV transmission through blood transfusion was estimated from data from Shenzhen, Hong Kong, and Taiwan as 14.11 (95\% confidence interval [CI], 11.00-17.22) per million, with a maximum risk of 23.57 (95\% CI, 6.83-47.69) per million [16].

SARS-CoV infection occurs through the binding of virus glycoprotein spikes to the receptors expressed by the pulmonary epithelial cells, followed by integration of the virus with the cell membrane. These receptors were identified as angiotensin-converting enzyme 2 (ACE-2) [17]. Interestingly, the receptor-binding motif of SARS$\mathrm{CoV}$ and the novel coronavirus are similar in sequence, strongly suggesting that COVID-19 transmission occurs by the entry of the virus into host cells by binding with ACE-2 receptors [18], which are abundantly present in the body in three main locations: pulmonary epithelial cells, enterocytes in the small intestine, and arterial and venous endothelial cells $[13,19]$. Chen et al. [13] had proposed that rampant coronavirus replication in pulmonary alveoli, via binding to the ACE- 2 receptors, results in the breakdown of the alveolar vessel and subsequent virus leakage into the blood flow, through which the virus is disseminated throughout the body, a mechanism that substantiates the presence and detection of the COVID-19 virus in the bloodstream. Given that ACE- 2 receptors are present only in the lungs and intestines, the transmission mode is primarily through the respiratory (and possibly oral) routes, given that they exclusively express the necessary receptor-binding sites. Thus, although the viral RNA is present in blood, direct blood-to-blood transmission is not pathophysiologically possible in the absence of a binding receptor. In contrast, aerosolized virus-containing blood particles from an infected patient can be inhaled by a recipient, wherein the virus would consequently bind to the ACE-2 receptors along the pulmonary epithelial cells and complete the viral transmission cycle, from the host's 
blood (patient) to the recipient's respiratory tract (the surgical team, in the current context) via blood-aerosols.

Amidst the current pandemic, the AABB (formerly the American Association of Blood Banks) released a statement that it did not find individuals at risk of contracting COVID-19 through the blood donation process or via a blood transfusion, given that respiratory viruses are generally not known to be transmitted by donation or transfusion [20]. Conversely, the Joint United Kingdom Blood Transfusion and Tissue Transplantation Services Professional Advisory Committee (JPAC) has issued clear guidelines prohibiting blood transfusions from confirmed coronavirus-infected donors and has stated that although there is no clear evidence at present on coronavirus transmission by blood, these measures are precautionary to avoid blood-borne transmission [21]. The policymakers' contrasting views highlight the ongoing debate and the need for further research into the exposure-infection causality to define the blood presence and stratify the risk of blood transmission of the novel COVID-19 virus.

While there is no direct evidence yet of direct blood-toblood COVID-19 transmission (as evidenced by a number of the transfusion guidelines), evidence gathered from SARS and MERS research indicates that the pathophysiology and molecular biochemical properties of coronaviral transmission and the conclusively reported bloodstream viremia clearly underline the presence of the COVID-19 virus in the blood. The bloodstream virus can be a potential source of transmission of the infection if the virusladen blood becomes aerosolized and subsequently enters the recipient host via inhalation into the respiratory tract to initiate its pathogenic cycle.

\section{Can spinal surgical techniques generate blood-aerosols?}

The modern spinal surgeon's armamentarium currently includes a wide range of specialized instruments, including osteotomes, high-speed drills, cutters, and bone scalpels, instruments that generally operate on high-frequency oscillations (cutters and bone scalpels), rotations (drills and burrs), or high impact (osteotomes). Procedures such as debridement and pulse lavage are also notorious for producing significant amounts of blood and fluid splatter. Although differing in their mechanism of action, the common factor uniting these instruments and procedures is their propensity to result in macroscopic blood splatter around the surgical field and, more importantly, the microscopic generation of particulate blood droplets from the operative field into the environment, which are known as "aerosols." These aerosols essentially reflect microparticles of the patient's blood and float in the air of the operating room, where they can remain suspended for a significant time and distance before eventually settling on a surface (human or inanimate). These otherwise innocuous particles are of concern if the host is either infected or a colonized carrier and consequently has transmissible pathogens in their bloodstream and thereby the surgical field. These particulate aerosols generated through the use of these instruments and techniques (during any spinal surgery) pose a contamination risk to the operating room's atmosphere and to the personnel present who can come into contact through mucocutaneous exposure.

Aerosol generation from high-speed drill instruments and their potential for transmitting diseases to healthcare personnel have been extensively studied in the field of dentistry, due to the obvious proximity of dentists to their patients' respiratory tract [22]. Outside the purview of dentistry, droplet infection transmission from surgical procedures and surgical instruments has been researched much more frequently in relation to human immunodeficiency virus (HIV) transmission and the transmission of iatrogenic wound infections [22-26]. Although direct surgical trauma and inoculation accounts for up to $75 \%$ of healthcare worker transmission [10], the transmission risk of airborne infection from infected hosts to recipients is still reported and evidenced for a variety of pathogens such as Mycobacterium tuberculosis, Staphylococcus aureus, Legionella, Varicella-zoster virus, Variola virus, and influenza virus $A$ [22,27-30]. Viruses have been reported to survive in the surgical smoke created by electrosurgical instruments [26,31]. In the subspecialty of orthopedics, operating room aerosol dissipation and potential contamination has been extensively studied and well established across a wide range of surgical procedures including hip arthroplasty $[32,33]$, lumbar spine surgery $[22,23]$, and cervical spine surgery [24].

Putzer et al. [23] studied aerosol generation and operating room contamination while using hydrotherapy and lavage during surgical procedures on thoracic spine cadaveric models using a $S$. aureus infective indicator and detected air contamination throughout the operating room, even to the room's periphery, including from inanimate objects. Among the operating room staff, the highest contamination from a thoracic spine surgical procedure 
was noted for the surgeon and surgeon's assistant, but no member of the operative room was free from the aerosol contamination, including the rest of the surgical team, the anesthetist (despite the presence of a draped barrier) and the patient's own head. Investigating the extent of the contamination spread, Putzer et al. [23] detected positive cultures over a $6 \times 8-\mathrm{m}$ area, while Nogler et al. [24] detected a spread over a $5 \times 7-\mathrm{m}$ area, noting that even a 170 $\mathrm{mm}$ drape between the surgical field and the anesthetist did not protect either the anesthetist or the patient's head from aerosol contamination. The authors postulated that the likely cause of this spread was not just due to the direct spray, which could be blocked by the drape, but was also likely a result of the aerosol cloud generated over the operative field by the use of the high-speed burr [24]. The use of positive pressure ventilation and laminar flow can also further dissipate such particles beyond the boundary of the operating room plenum.

Jewett et al. [25] assessed aerosol generation from common surgical tools in two clinical setups: one in bovine tissue in a laboratory and another in the Stanford T-cell infectivity culture study setup. The authors indirectly measured blood-aerosol generation from surgical wounds by measuring hemoglobin in the aerosolized particles as a marker for blood. The tested instruments were an oscillating saw, a high-speed air drill, a high-speed irrigating drill, and electrocautery in cutting and coagulation modes. The authors noted that all instruments produced aerosols of respirable range, which highlights the fact that it is not just the high-impact instruments that are capable of aerosolizing blood from operative wounds but also the basic surgical instruments (e.g., electrocautery, which has shown detectable blood particularization). Although spinal surgeons can choose not to use high-speed drills or high-impact instruments, evidence has shown that even basic surgical electrocautery generates enough aerosolized blood smog to be inhaled. If virus-laden, this aerosolized blood can potentially transmit a respiratory infection. Although the study was primarily conducted on HIV infection transmission, the biophysiological principles of aerosol generation can be extrapolated to any respirable infection, given that the same set of instruments tested in the study are still in use in modern spine surgery.

\section{Limitations}

In this extensive literature review, there are a number of limitations in establishing the notion of increased risk of virus transmission to surgical teams from the surgical site. Evidence from the early studies from China indicated blood COVID-19 viremia rates of 1\%-40\% [11-13]. These studies reported blood virus positivity based on the detection of viral RNA by quantitative reverse transcription (qRT)-PCR and not by direct viral culture, thereby raising the question of differentiating between infective and noninfective (dead or antibody-neutralized) viruses, which is one of the major limitations of nucleic acid detection tests [34]. This inability to identify the live COVID-19 virus in a patient's serum is a major factor in axiomatically considering the blood-aerosol transmission hypothesis of the viral cycle. Additionally, the contrasting guidelines between the AABB and JPAC on blood transfusion call into question the notion of a live viral presence in the blood and its transmission by aerosolized blood. However, evidence from SARS data suggests that the qRT-PCR viral assay provided critical prognostic value in clinical management and was positively related to the prediction of symptom severity and the need for intensive care and was an independent predictor of mortality [35]. Our current understanding of the viral RNA load kinetics and disease pathology of COVID-19 remains fragmented. However, based on the evidence-based presupposition that blood viral RNA load correlates with high levels of viral replication and given that Joynt and $\mathrm{Wu}$ [34] had indicated that because live viral cultures (unlike bacterial cultures) are technically quite difficult, especially during a pandemic, viral RNA load in clinical specimens can be employed as a surrogate marker for generating clinical hypotheses.

Also, there is no concrete evidence for causality as of yet, either supporting or refuting the transmission of the virus by aerosolized blood generated from the surgical site of infected patients, eventually causing symptomatic infection in a recipient. However, research on the subject is still in its nascent stages, and there is still a plethora of unknowns when it comes to the scientific community's understanding of the COVID-19 virus, the biology of its transmission, and the epidemiology of viral prevalence. Given the importance of risk assessment in policymaking decisions on the guidelines for protection and safety of front-line healthcare workers who provide the surgical care for patients undergoing aerosol-generating procedures, further funding should be dedicated by governments and healthcare organizations toward risk assessment, further investigations, and high-quality research in 
this field [36]. Until research studies have established the viral cycle in blood; however, it is worthwhile for spinal surgical teams to account for this potential additional surgical risk of exposure to the virus and act by instituting vigilant preventive measures.

\section{Conclusions}

Although the current consolidated evidence has focused on respiratory aerosol-generating procedures, this study underlines the fact that there is a definite presence of the COVID-19 virus in the bloodstream of infected patients. Conventional spinal surgical procedures, techniques, and instruments can generate blood-aerosol particles from the surgical wound, which contaminate the air and surfaces within the operating room and can be inhaled by the surgical team, especially the surgeon and surgical assistants closest to the patient. Any conclusions drawn from this review should be interpreted with caution, given that there is as yet no clinically validated evidence. However, there is substantive evidence in this review, albeit partly theoretical, suggesting the possibility of COVID-19 viral transmission via virus-laden blood-aerosols from an infected patient's surgical wound and the infection of surgical staff through aerosol inhalation and binding to pulmonary epithelial ACE-2 receptors. Unless incontrovertibly refuted, performing a spinal surgery exposes medical personnel in operating rooms to an additional risk of contracting the virus, above and beyond that posed by intubation and respiratory tract droplets.

Accounting for this purported additional risk, the surgical team should strictly adhere to strict PPE guidelines and measures, protecting themselves from additional exposure to aerosols generated while intraoperatively using electrosurgical, oscillating, and/or impacting equipment. These measures include those which prevent direct contact or exposure to aerosol smog such as the use of surgical hoods, face shields, and high filter capacity respirator masks (such as FF3) for surgeons and the rest of the surgical staff. Further steps can also be taken with the surgical techniques to mitigate this added hazard by minimizing surgical smoke through effective suctioning practices, using electrosurgical equipment at the lowest effective power, and preventing the pooling of blood in the operative field. Vigilant safety precautions and conscientious surgical practices should be a spinal surgeon's bastion against contracting the coronaviral disease.

\section{Conflict of Interest}

No potential conflict of interest relevant to this article was reported.

\section{Author Contributions}

All authors contributed equally to the conceptualization of the article, formulating the study outline, performing the literature review, analyzing the available evidence, writing of manuscript, and proofreading of the final submission.

\section{References}

1. Vannabouathong C, Devji T, Ekhtiari S, et al. Novel coronavirus COVID-19: current evidence and evolving strategies. J Bone Joint Surg Am 2020;102:734-44.

2. Huang C, Wang Y, Li X, et al. Clinical features of patients infected with 2019 novel coronavirus in $\mathrm{Wu}-$ han, China. Lancet 2020;395:497-506.

3. World Health Organization. WHO Director-General's opening remarks at the media briefing on COVID-19: 11 March 2020 [Internet]. Geneva: World Health Organization; 2020 [cited 2020 May 26]. Available from: https://www.who.int/dg/speeches/ detail/who-director-general-s-opening-remarks-atthe-media-briefing-on-covid-19---11-march-2020.

4. World Health Organization. Coronavirus disease (COVID-19): situation report-127 [Internet]. Geneva: World Health Organization; 2020 [cited 2020 May 26]. Available from: https://www.who.int/emergencies/diseases/novel-coronavirus-2019/situationreports.

5. Liu Z, Zhang Y, Wang X, et al. Recommendations for surgery during the novel coronavirus (COVID-19) epidemic. Indian J Surg 2020:1-5.

6. RCSI Surgical Affairs. Surgery during the COVID-19 pandemic: a guide to clinical practice for new or returning surgeons [Internet]. Dublin: Royal College of Surgeons in Ireland; 2020 [cited 2020 May 26]. Available from: https://www.rcsi.com/surgery/coronavirus/surgical-practice/clinical-guidance-for-surgeons.

7. Lo YT, Yang Teo NW, Ang BT. Editorial: endonasal neurosurgery during the COVID-19 pandemic: the Singapore perspective. J Neurosurg 2020 Apr 17 [Epub]. https://doi.org/10.3171/2020.4.JNS201036.

8. Centers for Disease Control and Prevention. Health- 
care Infection Prevention and Control FAQs for COVID-19 [Internet]. Atlanta (GA): Centers for Disease Control and Prevention; 2020 [cited 2020 May 26]. Available from: https://www.cdc.gov/ coronavirus/2019-ncov/hcp/infection-control-faq. html.

9. Royal College of Surgeons of England. COVID-19: good practice for surgeons and surgical teams [Internet]. London: Royal College of Surgeons of England; 2020 [cited 2020 May 26]. Available from: https://www.rcseng.ac.uk/standards-and-research/ standards-and-guidance/good-practice-guides/coronavirus/.

10. Wendlandt R, Thomas M, Kienast B, Schulz AP. In-vitro evaluation of surgical helmet systems for protecting surgeons from droplets generated during orthopaedic procedures. J Hosp Infect 2016;94:75-9.

11. Wang W, Xu Y, Gao R, et al. Detection of SARSCoV-2 in different types of clinical specimens. JAMA 2020;323:1843-4.

12. Zhang W, Du RH, Li B, et al. Molecular and serological investigation of 2019-nCoV infected patients: implication of multiple shedding routes. Emerg Microbes Infect 2020;9:386-9.

13. Chen W, Lan Y, Yuan X, et al. Detectable 2019$\mathrm{nCoV}$ viral RNA in blood is a strong indicator for the further clinical severity. Emerg Microbes Infect 2020;9:469-73

14. Chen H, Guo J, Wang C, et al. Clinical characteristics and intrauterine vertical transmission potential of COVID-19 infection in nine pregnant women: a retrospective review of medical records. Lancet 2020;395:809-15.

15. Zhu N, Zhang D, Wang W, et al. A novel coronavirus from patients with pneumonia in China, 2019. N Engl J Med 2020;382:727-3.

16. Chang L, Yan Y, Wang L. Coronavirus disease 2019: coronaviruses and blood safety. Transfus Med Rev 2020;34:75-80.

17. Wan Y, Shang J, Graham R, Baric RS, Li F. Receptor recognition by the novel coronavirus from Wuhan: an analysis based on decade-long structural studies of SARS coronavirus. J Virol 2020;94:e00127-20.

18. Jaimes JA, Millet JK, Stout AE, Andre NM, Whittaker GR. A tale of two viruses: the distinct spike glycoproteins of feline coronaviruses. Viruses 2020;12:83.

19. Hamming I, Timens W, Bulthuis ML, Lely AT, Navis
G, van Goor H. Tissue distribution of ACE2 protein, the functional receptor for SARS coronavirus: a first step in understanding SARS pathogenesis. J Pathol 2004;203:631-7.

20. Statement on coronavirus and blood donation [Internet]. Bethesda (MD): AABB; 2020 [cited 2020 May 26]. Available from: http://www.aabb.org/advocacy/ regulatorygovernment/Pages/Statement-on-Coronavirus-and-Blood-Donation.aspx.

21. Joint United Kingdom (UK) Blood Transfusion and Tissue Transplantation Services Professional Advisory Committee. Coronavirus infection [Internet]. Joint Base Pearl Harbor-Hickam: JPAC; 2020 [cited 2020 May 26]. Available from: https://www.transfusionguidelines.org/dsg/std/guidelines/coronavirusinfection-1.

22. Nogler M, Lass-Florl C, Ogon M, Mayr E, Bach C, Wimmer C. Environmental and body contamination through aerosols produced by high-speed cutters in lumbar spine surgery. Spine (Phila Pa 1976) 2001;26:2156-9.

23. Putzer D, Lechner R, Coraca-Huber D, Mayr A, Nogler M, Thaler M. The extent of environmental and body contamination through aerosols by hydro-surgical debridement in the lumbar spine. Arch Orthop Trauma Surg 2017;137:743-7.

24. Nogler M, Lass-Florl C, Wimmer C, Bach C, Kaufmann C, Ogon M. Aerosols produced by highspeed cutters in cervical spine surgery: extent of environmental contamination. Eur Spine J 2001;10:2747.

25. Jewett DL, Heinsohn P, Bennett C, Rosen A, Neuilly C. Blood-containing aerosols generated by surgical techniques: a possible infectious hazard. Am Ind Hyg Assoc J 1992;53:228-31.

26. Johnson GK, Robinson WS. Human immunodeficiency virus-1 (HIV-1) in the vapors of surgical power instruments. J Med Virol 1991;33:47-50.

27. Giachino A, Profitt A, Taine W. Contamination of the conjunctiva of the orthopaedic surgeon: a technical note. J Bone Joint Surg Am 1988;70:126-7.

28. Hadler SC. Hepatitis B virus infection and health care workers. Vaccine 1990;8 Suppl:S24-8.

29. Reboli AC, John JF Jr, Platt CG, Cantey JR. Methicillin-resistant Staphylococcus aureus outbreak at a Veterans' Affairs Medical Center: importance of carriage of the organism by hospital personnel. Infect Control 
Hosp Epidemiol 1990;11:291-6.

30. Walter CW, Kundsin RB, Brubaker MM. The incidence of airborne wound infection during operation. JAMA 1963;186:908-13.

31. Gloster HM Jr, Roenigk RK. Risk of acquiring human papillomavirus from the plume produced by the carbon dioxide laser in the treatment of warts. J Am Acad Dermatol 1995;32:436-41.

32. Nogler M, Wimmer C, Lass-Florl C, Mayr E, Trobos $\mathrm{S}$, Gegenhuber C. Contamination risk of the surgical team through ROBODOC's high-speed cutter. Clin Orthop Relat Res 2001;387:225-31.

33. Nogler M, Lass-Florl C, Wimmer C, Mayr E, Bach C, Ogon M. Contamination during removal of cement in revision hip arthroplasty: a cadaver study using ultrasound and high-speed cutters. J Bone Joint Surg Br 2003;85:436-9.

34. Joynt GM, Wu WK. Understanding COVID-19: what does viral RNA load really mean? Lancet Infect Dis 2020;20:635-6.

35. Bustin SA, Mueller R. Real-time reverse transcription PCR (qRT-PCR) and its potential use in clinical diagnosis. Clin Sci (Lond) 2005;109:365-79.

36. Tran K, Cimon K, Severn M, Pessoa-Silva CL, Conly J. Aerosol generating procedures and risk of transmission of acute respiratory infections to healthcare workers: a systematic review. PLoS One 2012;7:e35797. 